Dicle University Journal of Engineering (DUJE)

Araştırma Makalesi / Research Article

\title{
Bitki İndeksleri Kullanarak Buğday Bitkisinin Rekolte Tahmini
}

\section{Wheat Yield Estimation Using Vegetation Indices}

\author{
Yunus Kaya ${ }^{1 *}$, Nizar Polat ${ }^{1}$ \\ ${ }^{1}$ Harran Üniversitesi, Harita Mühendisliği Bölümü, Şanlıurfa, yunuskaya@ harran.edu.tr, nizarpolat@ harran.edu.tr
}

\begin{tabular}{|c|c|c|}
\hline \multicolumn{2}{|c|}{ MAKALE BİLGİLERİ } & ÖZET \\
\hline \multicolumn{2}{|c|}{ Makale geçmişi: } & $\begin{array}{l}\text { Uzaktan algılama, yer bazlı cihazlar, uçaklar veya uydular gibi uzak platformlardan yeryüzündeki nesneler } \\
\text { hakkında bilgi edinmeyi sağlayan bilim dalıdır. Uydu verileri farklı analizler yardımıyla ișlenerek çeșitli alanlarda }\end{array}$ \\
\hline Geliș: & 17 Şubat 2020 & kullanılabilmektedir. Uydu görüntülerinden elde edilen bitki örtüsü indeksleri yeryüzüne ilişkin farklı bilgiler \\
\hline Düzeltme: & 29 Temmuz 2020 & sağlamaktadır. Kuraklık haritalarının oluşturulması, ürün deseni belirleme çalışmaları, zamana bağlı ürün veya \\
\hline Kabul: & 30 Temmuz 2020 & bitki örtüsü değişimi çalışmaları bunlardan bazılarıdır. Gerek iklim koşullarının uygun olması gerekse de zengin \\
\hline \multicolumn{2}{|c|}{ Anahtar kelimeler: } & $\begin{array}{l}\text { tarım arazılerının olması sebebiyle, tarım Tükiye ekonomisı 1çn onemli bır alandır. Bu sebeple hem şlettme } \\
\text { sahipleri hem de ilgili bakanlıklar tarım arazilerinden maksimum verim alınması konusunda ilgilidirler. }\end{array}$ \\
\hline \multicolumn{2}{|c|}{$\begin{array}{l}\text { Uzaktan algılama, verim tahmin } \\
\text { modeli, buğday, bitki örtüsü indeksi }\end{array}$} & 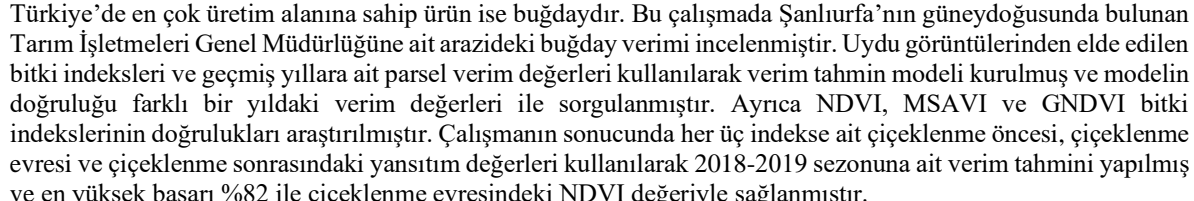 \\
\hline
\end{tabular}

Doi: $10.24012 /$ dumf. 860325

\begin{tabular}{|c|c|}
\hline ARTICLE INFO & ABSTRACT \\
\hline Article history: & \multirow{6}{*}{$\begin{array}{l}\text { Remote sensing is the science that provides information about objects on earth from remote platforms such as } \\
\text { ground-based devices, planes or satellites. Satellite data can be processed with different analyzes and used in } \\
\text { various fields. Vegetation indexes obtained from satellite images provide different information about the earth. } \\
\text { Some of these are drought maps creation, product pattern determination studies, time-dependent product or } \\
\text { vegetation change studies. Should not be appropriate due to the climatic conditions both in the rich agricultural } \\
\text { lands, agriculture is an important area for Turkey's economy. For this reason, both business owners and related } \\
\text { ministries are concerned with the maximum yield from agricultural land. Wheat is the most produced cereal in } \\
\text { Turkey. In this study, the wheat yield in the land belonging to the General Directorate of Agricultural Enterprises } \\
\text { located in the southeast of Sanliurfa was investigated. The yield estimation model was established using vegetation } \\
\text { indexes obtained from satellite images and parcel yield values from previous years and the accuracy of the model } \\
\text { were questioned with the yield values in a different year. In addition, the accuracy of NDVI, MSAVI and GNDVI } \\
\text { vegetation indexes were investigated. As a result of the study, the yield prediction for 2018-2019 season was made } \\
\text { using the reflection values of all three indices before flowering, in the flowering phase and after flowering, and } \\
\text { the highest success was achieved with } 82 \% \text { NDVI value in the flowering phase. }\end{array}$} \\
\hline Received: 17 February 2020 & \\
\hline 29 July 2020 & \\
\hline Accepted: 30 July 2020 & \\
\hline Keywords: & \\
\hline $\begin{array}{l}\text { Remote sensing, yield } \\
\text { estimation model, wheat, } \\
\text { vegetation indices }\end{array}$ & \\
\hline
\end{tabular}

\footnotetext{
* Sorumlu yazar / Correspondence

Yunus KAYA

$\triangle$ yunuskaya@harran.edu.tr
} 


\section{Giriş}

Günümüzde dünya nüfusu; sağlık alanındaki gelişmeler, insanların bilinçlenmesi vb. sebeplerden dolayı sürekli artmakta ve yaşam süresi uzamaktadır. Nüfusun artması ve doğal kaynakların yetersizliğinden dolayı tarım alanlarının ölçülmesi ve izlenmesi önemli bir hale gelmiştir [1]. Diğer yandan iklim koșullarının tarıma elverișli olması ve verimli topraklara sahip olmamı sebebiyle tarım, Türkiye ekonomisinde önemli bir yere sahiptir.

Buğday bitkisi dünya tahıl üretimi dikkate alındığında ikinci sırada yer alırken Türkiye tarımında en çok üretilen tahıl konumundadır. Türkiye İstatistik Kurumunun 2018 verilerine göre tahıl üretimi için ayrılan alanların \%62 sinde buğday yetiştirilmektedir. Üretim açısından incelendiğinde ise y1llık tahıl üretiminin \%37 sini buğday oluşturmaktadır (TÜİK 2018 raporu).

Tarım alanlarının verimli bir şekilde kullanılabilmesi için bu arazilerin belirli aralıklarla kontrol edilmesi ve mevcut durumlarının incelenmesi gerekmektedir. Uzaktan algilama teknikleri ve uydu verileri arazi örtüsünün belirlenmesinde [2], tarım arazilerinin izlenmesinde [3, 4], zamana bağl1 değişimlerin izlenmesinde $[5,6,7]$ ve rekolte tahmini çalışmalarında $[8,9,10]$ aktif olarak kullanılmaktadır. Uydu sistemleri üzerine yerleştirilen özel algılayıcılar sayesinde üretilen bitki indeksleri bitkinin gelişim evrelerinin incelenmesi ve verim tahmin modelinin kurulması için önemli katkılar sağlamaktadır. Geçmiş yıllara ait uydu görüntü verileri, hem geçmiş yıllara ilișkin tarım alanlarının belirlenmesinde hem de gelecek yıllara ilişkin tarım alanlarının yönetilmesine yardımc1 olmaktadır [11]. 1972 yilında Landsat-1 uydusunun firlatılmasıyla birlikte yeryüzüne ilişkin bilgilerin toplanmasında uzaktan algılama teknikleri kullanılmaya başlanmıştır. Landsat-1 uydusunun faaliyete geçmesinden sonra basit oran indeksine dayalı olarak çok sayıda bitki örtüsü indeksi bulunmuştur. Rouse vd. [12] ilk kez Normalize Edilmiş Bitki Örtüsü İndeksini (NDVI-Normalized Difference Vegetation Index) kullanmışlardır. Bitki örtüsü indeksleri kullanılarak gelecek yıllara ilişkin rekolte tahmini çalışmaları başlamıştır. Colwell vd. [13] ve Li [14] kışlık buğday verimini incelemek için Landsat uydu görüntüsünden yararlanmışlar. Özellikle büyük yüzölçümüne sahip alanlar için uzaktan algılama yaygın kullanılan bir yöntemdir $[15,16]$ ve belirli zaman aralıklarında elde edilen spektral değerler [17] ile hesaplanan bitki örtüsü indeksleri [18] buğday verimi tahmininde başarılı sonuçlar vermektedir $[19,20]$.

$\mathrm{Bu}$ çalışmada çiçeklenme öncesi, evresi ve sonrasinda belirlenecek verim tahmin modelinin doğruluğu araştırılmıștır. Ayrıca çalışmada farklı bitki örtüsü indekslerinin farklı evrelerdeki tutarlılığı araştırılmıştır.

\section{Çalışma alanı}

Çalışma alanı olarak Şanlıurfa ilinin güneydoğusundaki Ceylanpınar ilçesinde bulunan Tarım İşletmeleri Genel Müdürlüğü (TİGEM) arazisi seçilmiştir (Şekil 1). Sulu tarım yapılan buğday arazilerinden 5 adet ve kuru tarım yapılan buğday arazilerinden 3 adet olmak üzere toplam 8 adet parsel modelin oluşturulmasında kullanılmıştır. Parsellere ait verim değerleri Tablo 1'de verilmiştir.

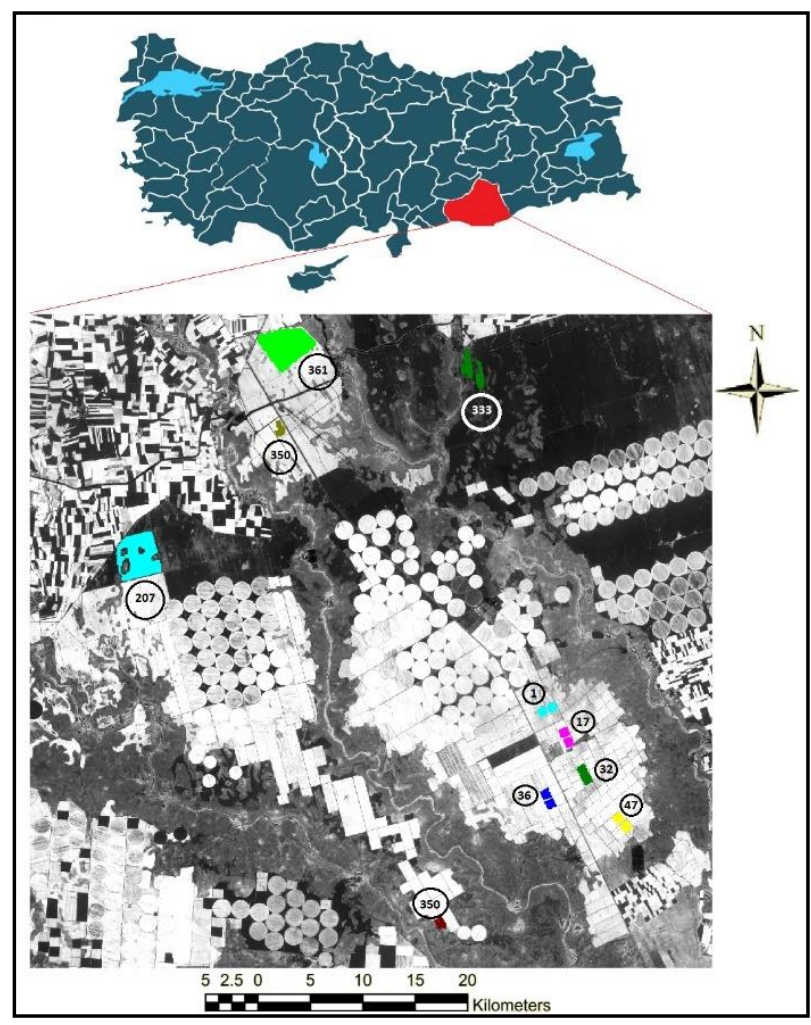

Şekil 1. Çalışma alanı(UTM-Zone:37) 
TİGEM arazisi 966 bin dekarı tarla arazisi olmak üzere 1,6 milyon dekar büyüklüğündedir ve Ceylanpınar ilçesinde bulunan TİGEM arazisinin yüzölçümü Türkiye genelinde bulunan TİGEM arazilerinin toplam yüzölçümünün yarısına eşittir (Tablo 2).

\section{Uydu verileri}

2016-2017 sezonu için belirlenen buğday tarlalarının izlenmesi için 2 adet Landsat- 8 ve 14 adet Sentinel-2 uydu verisi kullanılmıştır (Şekil 2). Landsat- 8 uydusuna ait genel özellikler Tablo 3 'te, Sentinel-2 uydusuna ait özellikler ise Tablo 4 'te verilmiştir. Kullanılan uydu verilerinin tarihleri Tablo 5'te verilmiştir.

Tablo 1. Parsel verim değerleri

\begin{tabular}{cccc}
\hline \multicolumn{2}{c}{ Sulu Tarım Arazisi } & \multicolumn{2}{c}{ Kuru Tarım Arazisi } \\
\hline Parsel Numaras1 & Verim $(\mathrm{kg} / \mathrm{da})$ & Parsel Numarasi & Verim $(\mathrm{kg} / \mathrm{da})$ \\
1 & 506,20 & 350 & 125,10 \\
17 & 558,40 & 354 & 37,30 \\
32 & 403,10 & 361 & 46,60 \\
36 & 371,80 & & \\
47 & 445,00 & & \\
\hline
\end{tabular}

Tablo 2. TIGGEM arazi alanları

\begin{tabular}{lrr}
\hline \multicolumn{1}{c}{ Arazi Türü } & $\begin{array}{c}\text { Ceylanpınar-Şanlıurfa } \\
\text { arazileri (da) }\end{array}$ & $\begin{array}{c}\text { Tüm TíGEM } \\
\text { arazileri (da) }\end{array}$ \\
\hline Tarla arazisi & 966436 & 2039362 \\
Tabii mera arazisi & 404433 & 629829 \\
Bahçe arazisi & 64512 & 120245 \\
Kültür altı arazi toplamı & 1435381 & 2789436 \\
Kültür dişı arazi & 198481 & 485637 \\
Sulanan arazi & 696568 & 942499 \\
Toplam arazi & 1633862 & 3275073 \\
\hline
\end{tabular}

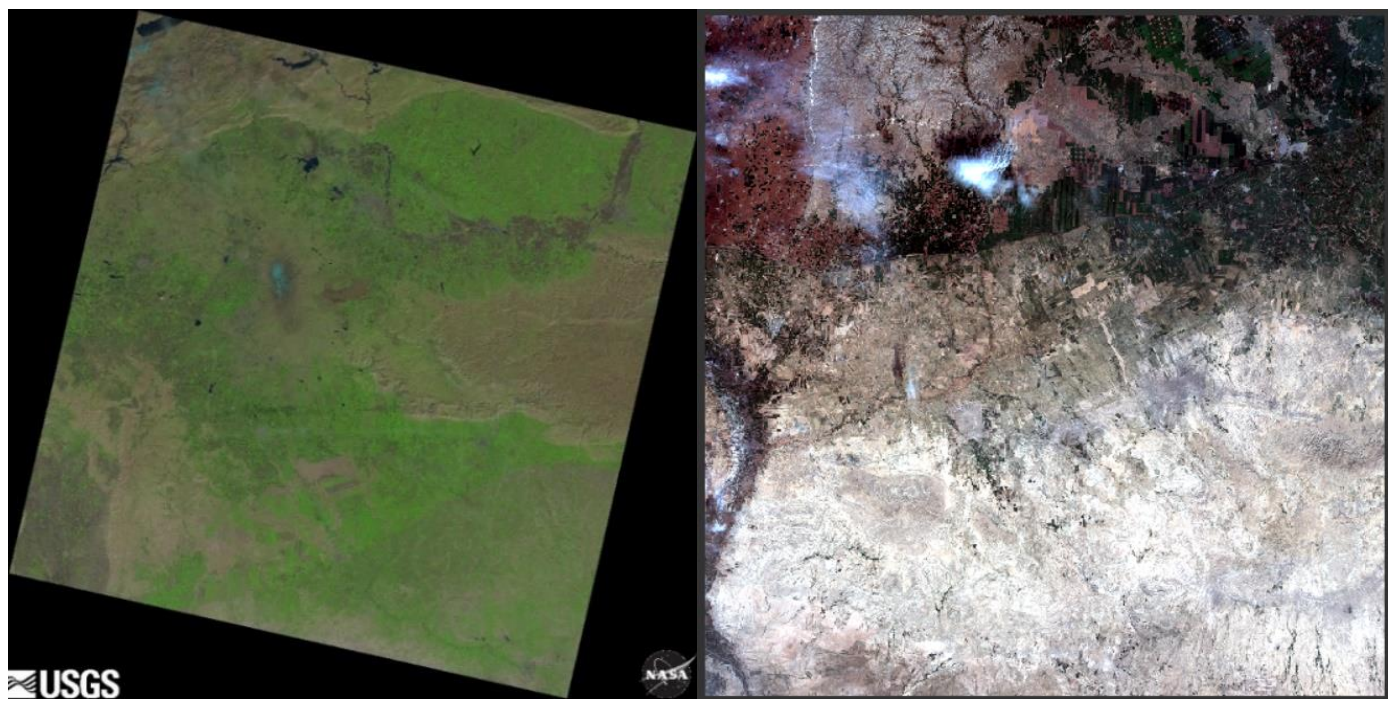

Şekil 2. Örnek Landsat [21] ve Sentinel [22] uydu görüntüsü ayak izi 
Tablo 3. Landsat 8 uydu özellikleri

\begin{tabular}{ccc}
\hline \multicolumn{3}{c}{ Landsat 8 OLI-TIRS } \\
\hline Şerit Genişliği $(\mathbf{k m})$ & \multicolumn{2}{c}{170 x 183} \\
\hline Radyometrik Çözünürlük (bit) & Dalga Boyu $(\boldsymbol{\mu m})$ & Çözünürlük (m) \\
\hline Landsat 8 & $0.43-0.45$ & 30 \\
Bant 1 & $0.45-0.51$ & 30 \\
Bant 2 & $0.53-0.59$ & 30 \\
Bant 3 & $0.64-0.67$ & 30 \\
Bant 4 & $0.85-0.88$ & 30 \\
Bant 5 & $1.57-1.65$ & 30 \\
Bant 6 & $2.11-2.29$ & 30 \\
Bant 7 & $0.50-0.68$ & 15 \\
Bant 8 & $1.36-1.38$ & 30 \\
Bant 9 & $10.6-11.19$ & 100 \\
Bant 10 & $11.50-12.51$ & 100 \\
Bant 11 & & \\
\hline
\end{tabular}

Tablo 4. Sentinel 2 uydu özellikleri

\begin{tabular}{|c|c|c|}
\hline \multicolumn{3}{|c|}{ SENTINEL-2 } \\
\hline \multicolumn{2}{|c|}{ Radyometrik Çözünürlük (bit) } & \multirow{2}{*}{$\begin{array}{c}8 \\
\text { Çözünürlük (m) }\end{array}$} \\
\hline Sentinel-2 & Dalga Boyu $(\mu \mathrm{m})$ & \\
\hline Bant 1- Kıyı Aerosolü & 0.443 & 60 \\
\hline Bant 2-Mavi & 0.49 & 10 \\
\hline Bant 3- Yeşil & 0.56 & 10 \\
\hline Bant 4- Kırmızı & 0.665 & 10 \\
\hline Bant 5- Kırmızı Kenar (Red Edge) & 0.705 & 20 \\
\hline Bant 6- Kırmızı Kenar (Red Edge) & 0.74 & 20 \\
\hline Bant 7- Kırmızı Kenar (Red Edge) & 0.783 & 20 \\
\hline Bant 8- Yakin Infrared (NIR) & 0.842 & 10 \\
\hline Bant 8A- Kırmız1 Kenar (Red Edge) & 0.865 & 20 \\
\hline Bant 9- Su Buharı & 0.945 & 60 \\
\hline Bant 10- Kisa Dalga Infrared (SWIR) & 1.375 & 60 \\
\hline Bant 11- Kisa Dalga Infrared (SWIR) & 1.610 & 20 \\
\hline Bant 12- Kisa Dalga Infrared (SWIR) & 2.190 & 20 \\
\hline
\end{tabular}

Tablo 5. Kullanılan uydu verilerinin tarihleri

\begin{tabular}{cccc}
\hline \multicolumn{3}{c}{ 2017-2018 Sezonu } & \\
\hline \multirow{2}{*}{ ARALIK } & 4.12 .2017 & \multirow{2}{*}{ NISSAN } & 8.04 .2018 \\
& 8.12 .2017 & & 13.04 .2018 \\
\multirow{2}{*}{ OCAK } & 14.12 .2017 & \multirow{2}{*}{ MAYIS } & 23.04 .2018 \\
\hline \multirow{2}{*}{ ŞUBAT } & 9.01 .2018 & & 18.05 .2018 \\
& 13.01 .2018 & \multirow{2}{*}{ HAZİRAN } & 23.05 .2018 \\
\hline \multirow{2}{*}{ MART } & 2.02 .2018 & & 7.06 .2018 \\
& \multirow{2}{*}{19.03 .2018} & & 17.06 .2018 \\
& & & 22.06 .2018 \\
\hline
\end{tabular}




\section{Bitki örtüsü indeksleri}

Buğday bitkisine ait yansıtımları belirlemek için NDVI, MSAVI ve GNDVI indeksleri kullanılmıştır. NDVI [11] bant aritmetiği, elektromanyetik spektrumun yakın kızılötesi ve kırmızı dalga boyundaki 1 şı değerlerinin birbirinden çıkarılıp daha sonra iki bandın toplamına bölünmesiyle elde edilir [23] ve en çok kullanılan bitki indekslerindendir [24]. NDVI (1) eşitliği ile hesaplanır.

Toprak Ayarlı Bitki Örtüsü İndeksi (SoilAdjusted Vegetation Index-SAVI) toprak etkisinin de dikkate alındığı bir indekstir. Bundan dolayı formülünde arka plan ayar faktörü olarak L parametresini barındırır. Bitki örtüsünün yoğun olduğu arazilerde L değeri 0 ya da 0 'a çok yakın bir değer alırken bitki örtüsünün seyrek olduğu yerlerde L değeri 1 veya 1'e yakın değerler almaktadır. Ancak belirlenen bu sabit L değeri bitki örtüsü yapısının homojen olmamasından kaynaklı olarak her zaman aynı doğruluğu sağlamamaktadır. $\mathrm{Bu}$ nedenle toprağın etkisine en uygun ayarın elde edilmesi için L arka plan ayar faktörünün mevcut bitki örtüsü miktarına göre değişmesi gerekmektedir. $\mathrm{Bu}$ şekilde tanımlanan ve Modifiye Edilmiş Toprak Ayarlı Bitki Örtüsü İndeksi (Modified Soil Adjusted Vegetation Index-MSAVI) olarak adlandırılan indeks (2) eşitliği ile hesaplanır.

Yeşil Normalize Edilmiş Bitki Örtüsü İndeksi (Green Normalized Difference Vegetation
Index-GNDVI) ise NDVI'dan farkl1 olarak kırmızı dalga boyu yerine yeşil dalga boyunu kullanır ve (3) eşitliği ile hesaplanır(Tablo 6).

\section{Uygulama}

\section{Görüntülerin işlenmesi ve değerlendirilmesi}

Landsat uydusundan elde edilen görüntüler ENVI (Environment for Visualizing Images) yazılımında, Sentinel uydusundan elde edilen görüntüler ise SNAP (Sentinel Application Platform) yazılımında değerlendirilerek NDVI histogramları oluşturulmuş ve sayısal olarak dışarıya aktarılmıştır. Optik uydu görüntülerinin handikaplarından birisi bulutlu havalarda ve yeryüzündeki yansıyıcı yüzeylerden kaynaklı olarak bazı piksellerin gerçek değerden farklı çıkmasıdır. Dolayısıyla çalışmada kullanılan piksel değerlerinde ortalamadan çok uzakta değer alan piksellerin elenmesi bu ilgisiz piksellerin temizlenmesi için gereklidir. Aktarılan veriler içinde ilgisiz indeks değerlerine sahip pikseller ayıklanmıştır. $\mathrm{Bu}$ işlem belirlenirken her parsel için mevcut piksel sayısındaki indeks değerlerine bakılmıştır ve piksel sayısının \%5 i kadar piksel elenmiştir. Eleme işlemi indeks değerinin alt ve üst sınırından alınmıştır (Şekil 3). Geriye kalan indeks değerleri yardımıyla ağırlıklı ortalama indeks değeri bulunmuştur. Çalışmada bant oranlaması kullanıldığı için topoğrafik düzeltme yapılmamıştır.

Tablo 6. Kullanılan bitki örtüsü indeksleri

\begin{tabular}{lcc}
\hline \multicolumn{1}{c}{ Indeks } & Formül & Kaynak \\
\hline $\begin{array}{l}\text { (1) Normalize Edilmiş } \\
\text { Bitki Örtüsü İndeksi }\end{array}$ & NDVI $=\frac{N I R-\text { Red }}{N I R+\text { Red }}$ & Rouse vd. [12] \\
$\begin{array}{lc}\text { (2) Modifiye Edilmiş } \\
\text { Toprak Ayarlı Bitki }\end{array}$ & MSAVI $=\frac{2 x N I R+1-\sqrt{(2 x N I R+1)^{2}-8(\mathrm{NIR}-\text { Red })}}{2}$ & $\begin{array}{l}\text { Richardson ve } \\
\text { Wiegand [25] }\end{array}$ \\
$\begin{array}{l}\text { Örtüsü İndeksi } \\
\text { (3) Yeşil Normalize }\end{array}$ & Gitelson [26] \\
Edilmiş Bitki Örtüsü & GNDVI $=\frac{N I R-\text { Green }}{N I R+\text { Green }}$ & \\
İndeksi & & \\
\hline
\end{tabular}




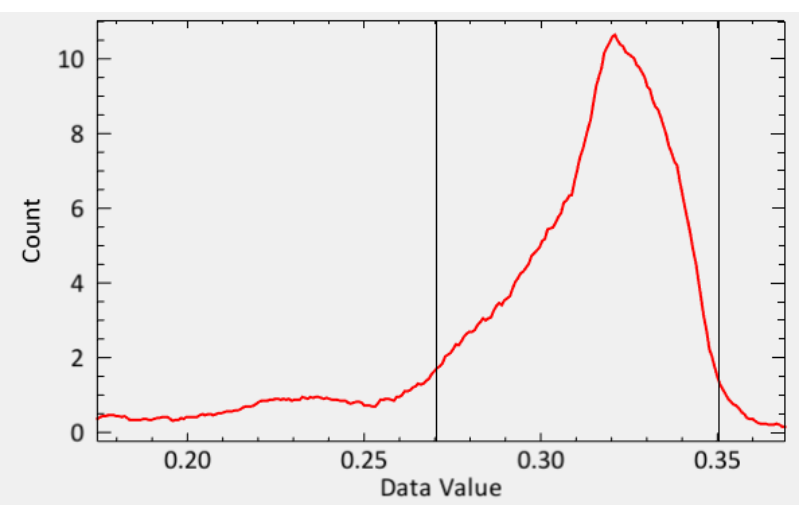

Şekil 3. Örnek histogram grafiği(NDVI)

\section{Fenolojik evrelerin belirlenmesi}

Buğday bitkisinin gelişim evreleri temel olarak 4 aşamada incelenebilir. Bunlar; çimlenme ve fide aşaması, kardeşlenme ve kök uzaması, çiçeklenme ve olgunlaşma aşamalarıdır. $\mathrm{Bu}$ aşamalardan önemli olanı ise çiçeklenme aşamasıdır. Çünkü buğday bitkisi çiçeklenme aşamasında en yeşil formuna ulaşır ve NDVI değeri maksimum seviyede olur. Bundan dolayı NDVI değerinin maksimum değere ulaştı̆̆ tarihler çiçeklenme evresi olarak kabul edilmiştir. Çiçeklenme öncesinden bir önceki uydu görüntüsünün tarihi çiçeklenme öncesi, bir sonraki uydu görüntüsünün tarihi ise çiçeklenme sonras1 olarak kabul edilmiştir. 2017-2018 sezonuna ait sulu ve kuru tarım yapılan tarlalardaki NDVI değerleri sırasıyla Şekil 4 ve Şekil 5'te gösterilmiştir.

Şekil 4 ve 5 'ten incelendiğinde NDVI değerinin maksimuma ulaştığı tarih (08.04.2018) çiçeklenme evresi olarak belirlenmiştir. Buna göre 19.03.2018 tarihi çiçeklenme öncesi, 18.05.2018 tarihi de çiçeklenme sonrası olarak kabul edilmiştir. Çalışmada kullanılan indeks değerleri Tablo 7'de verilmiştir.

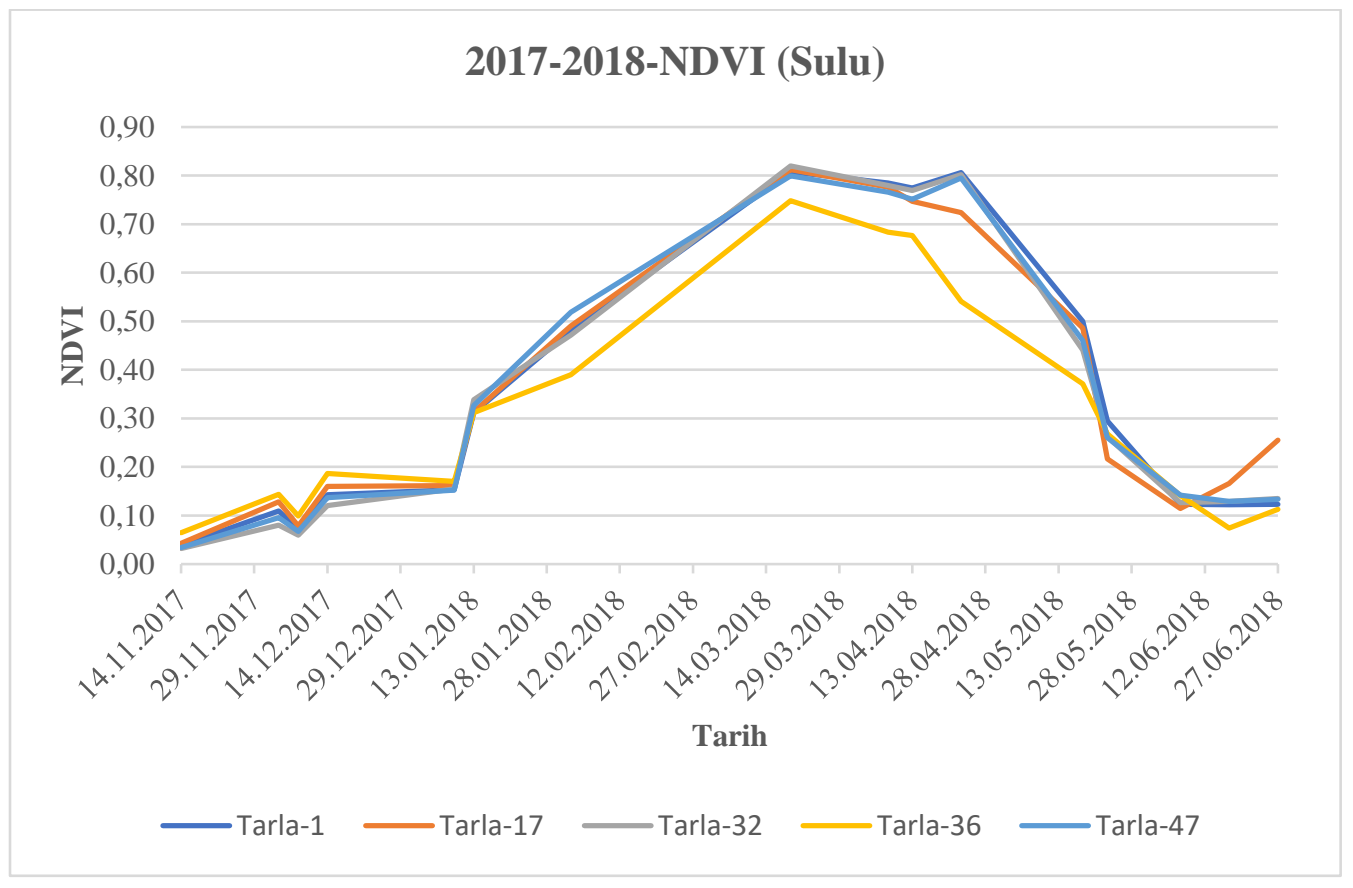

Şekil 4. 2017-2018 sezonu sulu parsellere ait NDVI grafiği 


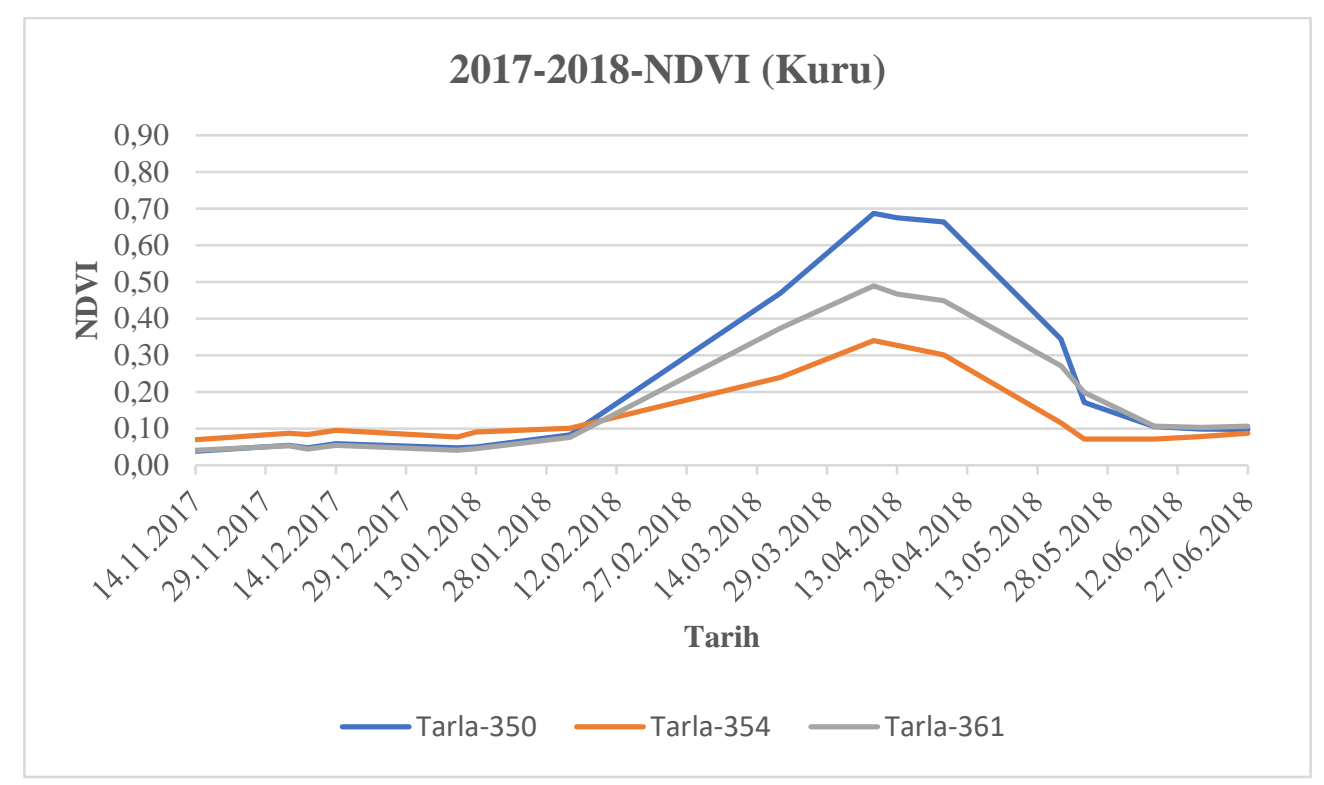

Şekil 5. 2017-2018 sezonu kuru parsellere ait NDVI grafiği

Tablo 7. Farklı evrelerdeki indeks değerleri

\begin{tabular}{ccccc}
\hline Indeks & Tarla & Çiçeklenme öncesi & Çiçeklenme evresi & Çiçeklenme sonrası \\
\hline & $\mathbf{1}$ & 0.48 & 0.81 & 0.50 \\
& $\mathbf{1 7}$ & 0.49 & 0.81 & 0.49 \\
NDVI & $\mathbf{3 2}$ & 0.47 & 0.82 & 0.44 \\
& $\mathbf{3 6}$ & 0.39 & 0.75 & 0.37 \\
& $\mathbf{4 7}$ & 0.52 & 0.80 & 0.46 \\
& $\mathbf{3 5 0}$ & 0.47 & 0.69 & 0.34 \\
& $\mathbf{3 5 4}$ & 0.24 & 0.34 & 0.12 \\
& $\mathbf{3 6 1}$ & 0.37 & 0.49 & 0.27 \\
\hline \multirow{6}{*}{ GNDVI } & $\mathbf{1}$ & 0.42 & 0.68 & 0.45 \\
& $\mathbf{1 7}$ & 0.44 & 0.68 & 0.36 \\
& $\mathbf{3 2}$ & 0.41 & 0.69 & 0.41 \\
& $\mathbf{3 6}$ & 0.38 & 0.46 & 0.42 \\
& $\mathbf{3 5 0}$ & 0.44 & 0.67 & 0.43 \\
& $\mathbf{3 5 4}$ & 0.46 & 0.35 & 0.60 \\
& $\mathbf{3 6 1}$ & 0.30 & 0.27 & 0.28 \\
& $\mathbf{1}$ & 0.41 & 0.36 & 0.56 \\
\hline \multirow{6}{*}{ MSA VI } & $\mathbf{1 7}$ & 0.27 & 0.62 & 0.28 \\
& $\mathbf{3 2}$ & 0.28 & 0.68 & 0.18 \\
& $\mathbf{3 6}$ & 0.23 & 0.64 & 0.24 \\
& $\mathbf{4 7}$ & 0.28 & 0.35 & 0.26 \\
& $\mathbf{3 5 0}$ & 0.27 & 0.60 & 0.25 \\
& $\mathbf{3 6 1}$ & 0.11 & 0.17 & 0.48 \\
& & 0.21 & 0.06 & 0.08 \\
& & & 0.15 & 0.41 \\
\hline
\end{tabular}




\section{Verim tahmin modeli}

Buğday alanları için NDVI, GNDVI ve MSAVI değerleri göz önüne alınarak doğrusal regresyon analizi yapılarak verim tahmin modeli kurulmuştur. Kurulan modelde buğdayın çiçeklenme öncesi, çiçeklenme evresi ve çiçeklenme sonrasındaki indeks değerleri ile verim değerleri arasında ilişki kurulmuştur. Parsellere ait verim değerleri TİGEM'den temin edilmiştir. Verim denklemleri, korelasyon katsayıları (r) ve determinasyon katsayıları $\left(\mathrm{r}^{2}\right)$ değerleri Tablo 8'de verilmiştir.

Tablo 8 incelendiğinde en yüksek korelasyon değerinin MSAVI'de $(0,96)$ olduğu görülmektedir. Genel olarak korelasyon değerleri incelendiğinde MSAVI ve GNDVI indekslerinde çiçeklenme evresinde diğer evrelere göre büyük bir fark gözükmektedir. NDVI'da ise çiçeklenme evresi ve çiçeklenme sonrasında yüksek korelasyon gözlenmiştir.

\section{Doğruluk analizi}

2017-2018 sezonundaki belirli parsellerdeki verim değerleri ile yansıtım değerleri arasında uygulanan doğrusal regresyon modeli sonucu elde edilen denklem değerleri 2018-2019 sezonundaki buğday verim tahmini için uygulanmıştır. Elde edilen indeks değerleri incelenerek çiçeklenme öncesi, çiçeklenme evresi ve çiçeklenme sonrası belirlenmiş ve bu tarihlerdeki tüm indeks değerleri verim modelinde elde edilen denkleme uygulanmıştır. Tablo 8'de verilen verim denklemleri kullanılarak 2018-2019 sezonuna ait verim değerleri tahmin edilmiştir. Daha sonra elde edilen tahmini verim değerleri TİGEM'den alınan gerçek verim değerleriyle karşılaştırılmıştır. Doğruluk oranları (4) eşitliği ile elde edilmiştir. Sonuçlar NDVI, MSAVI ve GNDVI değerleri için sırasıyla Tablo 9, 10 ve 11 'de verilmiştir.

Tablo 8. Farklı evrelerdeki verim denklem değerleri

\begin{tabular}{|c|c|c|c|c|}
\hline Indeks & Evre & Denklem & $\begin{array}{c}\text { Korelasyon } \\
\text { Katsayısı (r) }\end{array}$ & $\begin{array}{c}\text { Determinasyon } \\
\text { Katsayısı }\left(\mathbf{r}^{2}\right)\end{array}$ \\
\hline \multirow{3}{*}{ NDVI } & Çiçeklenme Öncesi & $1680,5 x-409,61$ & 0,73 & 0,53 \\
\hline & Çiçeklenme Evresi & $1040,5 x-404,18$ & 0,89 & 0,78 \\
\hline & Çiçeklenme Sonrası & $1461,6 x-234,37$ & 0,91 & 0,82 \\
\hline \multirow{3}{*}{ MSAVI } & Çiçeklenme Öncesi & $2726,6 x-304,42$ & 0,69 & 0,48 \\
\hline & Çiçeklenme Evresi & $878,82 x-15,606$ & 0,96 & 0,92 \\
\hline & Ciçeklenme Sonras1 & $-481,48 x+435,36$ & 0,26 & 0,07 \\
\hline \multirow{3}{*}{ GNDVI } & Çiçeklenme Öncesi & $1505,1 x-386,5$ & 0,41 & 0,17 \\
\hline & Çiçeklenme Evresi & $943,3 x-259,13$ & 0,93 & 0,87 \\
\hline & Çiçeklenme Sonrası & $-470,52 x+562,23$ & 0,28 & 0,08 \\
\hline
\end{tabular}

Model Doğruluğu $=\left(1-\frac{\mid \text { Tahmini verim }- \text { Gerçek verim } \mid}{\text { Gerçek verim }}\right) * 100$ 
Tablo 9. Doğruluk analizi(NDVI)

\begin{tabular}{|c|c|c|c|c|c|c|}
\hline EVRE & Tarla & NDVI & $\begin{array}{c}\text { Tahmini Verim } \\
(\mathrm{kg} / \mathrm{da})\end{array}$ & $\begin{array}{c}\text { Gerçek Verim } \\
(\mathrm{kg} / \mathrm{da})\end{array}$ & $\begin{array}{c}\text { Doğruluk } \\
\text { Oranı (\%) } \\
\end{array}$ & $\begin{array}{l}\text { Doğruluk } \\
\text { Ort. }(\%) \\
\end{array}$ \\
\hline \multirow{7}{*}{$\begin{array}{l}\text { Çiçeklenme } \\
\text { Öncesi }\end{array}$} & 1 & 0.41 & 279.4 & 459.6 & 60.8 & \multirow{7}{*}{56} \\
\hline & 17 & 0.51 & 447.4 & 268.5 & 33.4 & \\
\hline & 32 & 0.36 & 195.4 & 202.9 & 96.3 & \\
\hline & 36 & 0.53 & 481.1 & 265.0 & 18.5 & \\
\hline & 47 & 0.38 & 229.0 & 219.8 & 95.8 & \\
\hline & 207 & 0.53 & 481.1 & 340.5 & 58.7 & \\
\hline & 333 & 0.58 & 565.1 & 324.8 & 26.0 & \\
\hline \multirow{7}{*}{$\begin{array}{l}\text { Çiçeklenme } \\
\text { Evresi }\end{array}$} & 1 & 0.75 & 376.2 & 459.6 & 81.9 & \multirow{7}{*}{82} \\
\hline & 17 & 0.71 & 334.6 & 268.5 & 75.4 & \\
\hline & 32 & 0.49 & 105.7 & 202.9 & 52.1 & \\
\hline & 36 & 0.68 & 303.4 & 265.0 & 85.5 & \\
\hline & 47 & 0.63 & 251.3 & 219.8 & 85.7 & \\
\hline & 207 & 0.73 & 355.4 & 340.5 & 95.6 & \\
\hline & 333 & 0.71 & 334.6 & 324.8 & 97.0 & \\
\hline \multirow{7}{*}{$\begin{array}{l}\text { Çiçeklenme } \\
\text { Sonrası }\end{array}$} & 1 & 0.64 & 701.1 & 459.6 & 47.5 & \multirow{7}{*}{60} \\
\hline & 17 & 0.46 & 438.0 & 268.5 & 36.9 & \\
\hline & 32 & 0.34 & 262.6 & 202.9 & 70.6 & \\
\hline & 36 & 0.41 & 364.9 & 265.0 & 62.3 & \\
\hline & 47 & 0.29 & 189.5 & 219.8 & 86.2 & \\
\hline & 207 & 0.29 & 189.5 & 340.5 & 55.7 & \\
\hline & 333 & 0.3 & 204.1 & 324.8 & 62.8 & \\
\hline
\end{tabular}

Tablo10. Doğruluk analizi(MSAVI)

\begin{tabular}{|c|c|c|c|c|c|c|}
\hline EVRE & Tarla & MSAVI & $\begin{array}{c}\text { Tahmini Verim } \\
\text { (kg/da) }\end{array}$ & $\begin{array}{c}\text { Gerçek Verim } \\
\text { (kg/da) }\end{array}$ & $\begin{array}{l}\text { Doğruluk } \\
\text { Oranı (\%) }\end{array}$ & $\begin{array}{l}\text { Doğruluk } \\
\text { Ort. }(\%)\end{array}$ \\
\hline \multirow{7}{*}{$\begin{array}{l}\text { Çiçeklenme } \\
\text { Öncesi }\end{array}$} & 1 & 0.23 & 92.7 & 459.6 & 20.2 & \multirow{7}{*}{63} \\
\hline & 17 & 0.31 & 230.8 & 268.5 & 86.0 & \\
\hline & 32 & 0.22 & 75.4 & 202.9 & 37.2 & \\
\hline & 36 & 0.33 & 265.4 & 265.0 & 99.9 & \\
\hline & 47 & 0.24 & 110.0 & 219.8 & 50.0 & \\
\hline & 207 & 0.34 & 282.6 & 340.5 & 83.0 & \\
\hline & 333 & 0.3 & 213.6 & 324.8 & 65.8 & \\
\hline \multirow{7}{*}{$\begin{array}{l}\text { Çiçeklenme } \\
\text { Evresi }\end{array}$} & 1 & 0.53 & 397.2 & 459.6 & 86.4 & \multirow{7}{*}{76} \\
\hline & 17 & 0.5 & 373.8 & 268.5 & 60.8 & \\
\hline & 32 & 0.33 & 241.4 & 202.9 & 81.0 & \\
\hline & 36 & 0.45 & 334.9 & 265.0 & 73.6 & \\
\hline & 47 & 0.44 & 327.1 & 219.8 & 51.2 & \\
\hline & 207 & 0.51 & 381.6 & 340.5 & 87.9 & \\
\hline & 333 & 0.48 & 358.2 & 324.8 & 89.7 & \\
\hline \multirow{7}{*}{$\begin{array}{l}\text { Çiçeklenme } \\
\text { Sonrası }\end{array}$} & 1 & 0.42 & 233.1 & 459.6 & 50.7 & \multirow{7}{*}{71} \\
\hline & 17 & 0.3 & 290.9 & 268.5 & 91.7 & \\
\hline & 32 & 0.21 & 334.2 & 202.9 & 35.3 & \\
\hline & 36 & 0.25 & 315.0 & 265.0 & 81.1 & \\
\hline & 47 & 0.19 & 343.9 & 219.8 & 43.5 & \\
\hline & 207 & 0.19 & 343.9 & 340.5 & 99.0 & \\
\hline & 333 & 0.19 & 343.9 & 324.8 & 94.1 & \\
\hline
\end{tabular}


Tablo11. Doğruluk analizi(GNDVI)

\begin{tabular}{|c|c|c|c|c|c|c|}
\hline EVRE & Tarla & GNDVI & $\begin{array}{c}\text { Tahmini Verim } \\
(\mathrm{kg} / \mathrm{da})\end{array}$ & $\begin{array}{c}\text { Gerçek Verim } \\
(\mathrm{kg} / \mathrm{da})\end{array}$ & \begin{tabular}{|l|} 
Doğruluk \\
Oranı (\%) \\
\end{tabular} & $\begin{array}{l}\text { Doğruluk } \\
\text { Ort. }(\%) \\
\end{array}$ \\
\hline \multirow{7}{*}{$\begin{array}{l}\text { Çiçeklenme } \\
\text { Öncesi }\end{array}$} & 1 & 0.3 & 65.0 & 459.6 & 14.1 & \multirow{7}{*}{55} \\
\hline & 17 & 0.44 & 275.7 & 268.5 & 97.3 & \\
\hline & 32 & 0.34 & 125.2 & 202.9 & 61.7 & \\
\hline & 36 & 0.52 & 396.2 & 265.0 & 50.5 & \\
\hline & 47 & 0.39 & 200.5 & 219.8 & 91.2 & \\
\hline & 207 & 0.65 & 591.8 & 340.5 & 26.2 & \\
\hline & 333 & 0.6 & 516.6 & 324.8 & 41.0 & \\
\hline \multirow{7}{*}{$\begin{array}{l}\text { Çiçeklenme } \\
\text { Evresi }\end{array}$} & 1 & 0.45 & 165.4 & 459.6 & 36.0 & \multirow{7}{*}{63} \\
\hline & 17 & 0.63 & 335.1 & 268.5 & 75.2 & \\
\hline & 32 & 0.41 & 127.6 & 202.9 & 62.9 & \\
\hline & 36 & 0.52 & 231.4 & 265.0 & 87.3 & \\
\hline & 47 & 0.58 & 288.0 & 219.8 & 69.0 & \\
\hline & 207 & 0.49 & 203.1 & 340.5 & 59.6 & \\
\hline & 333 & 0.44 & 155.9 & 324.8 & 48.0 & \\
\hline \multirow{7}{*}{$\begin{array}{l}\text { Çiçeklenme } \\
\text { Sonrası }\end{array}$} & 1 & 0.42 & 364.6 & 459.6 & 79.3 & \multirow{7}{*}{62} \\
\hline & 17 & 0.5 & 327.0 & 268.5 & 78.2 & \\
\hline & 32 & 0.35 & 397.5 & 202.9 & 4.1 & \\
\hline & 36 & 0.54 & 308.1 & 265.0 & 83.7 & \\
\hline & 47 & 0.41 & 369.3 & 219.8 & 32.0 & \\
\hline & 207 & 0.33 & 407.0 & 340.5 & 80.5 & \\
\hline & 333 & 0.32 & 411.7 & 324.8 & 73.3 & \\
\hline
\end{tabular}

Tablo 8 incelendiğinde en yüksek indeks-verim korelasyonu çiçeklenme evresinde olduğu görülmektedir. Tablo 9, 10 ve 11 incelendiğinde de verim tahmininin her üç indeks için çiçeklenme evresinde gerçeğe daha yakın bir doğrulukta gerçekleştiği görülmektedir. En yüksek doğruluk (\%82) çiçeklenme evresinde NDVI indeksinde görülmektedir. MSAVI indeksinin çiçeklenme evresinde \%76'lık, GNDVI indeksinin çiçeklenme evresinde ise \%63 lük bir doğruluk elde edilmiştir. Korelasyon katsayılarından ve doğruluk analizinden anlaş1lacağı üzere buğday bitkisine ilişkin verim tahmin değerleri çiçeklenme evresinde diğer evrelere göre daha sağlıklı sonuçlar vermektedir.

\section{Sonuçlar}

Büyük tarım arazilerine ve verimli topraklara sahip ülkemizde tarım alanlarının korunması ve mevcut tarım arazilerinin en iyi şekilde kullanılması ülke tarımı ve ekonomisi için önemlidir. Temel yaşam gıdalarından biri olan buğday Türkiye'de en çok üretimi yapılan tahıl konumundadır. $\mathrm{Bu}$ sebeple buğday bitkisinin büyüme evrelerinin takip edilmesi ve rekoltenin hasattan önce belirlenmesi tarımsal politikaların belirlenmesi için önem taşımaktadır.

Uydu sistemleri farklı dalga boylarında enerji kaydedebilen algılayıcılarla donatıldıkları için bitki örtüsü hakkında faydalı bilgiler sunmaktadır. NDVI, GNDVI ve MSAVI indeksleri kullanılarak bitkilerdeki klorofil maddesinin yansıtımı yardımıyla bitkilerin yeşillik durumları analiz edilir. $\mathrm{Bu}$ şekilde arazideki bitki örtüsü yoğunluğu belirlenir ve bitkilerin sağlık düzeyleri kontrol edilebilir.

Bu çalışmada Şanlıurfa ili Ceylanpınar ilçesinde bulunan TİGEM arazisinde bulunan buğday tarlalarının fenolojik evreleri incelenmiştir. Ayrica 2017-2018 sezonundaki uydu görüntülerinden elde edilen bitki örtüsü indeksi değerleri ve verim değerleri kullanılarak verim tahmin modeli geliştirilmiştir. Geliştirilen bu 
model 2018-2019 sezonunda belirli parseller için uygulanmış ve verim değerleri ortalama olarak çiçeklenme evresinde NDVI'da 82, MSAVI'de $\% 76$, GNDVI'da ise \%63 doğruluk ile elde edilmiştir. İndeks-verim denklemleri incelendiğinde en yüksek korelasyon çiçeklenme evresinde MSAVI'de (\%96) gözlemlenmiştir.

Çalışmada belirli bir yıla ilişkin uydu görüntüleri kullanılarak verim tahmin modelinin başarısı üzerinde durulmuştur. İleriki çalışmalarda farklı y1llardan elde edilen uydu görüntüleri ve farklı yapılara sahip bitki örtüsü indekslerinin kullanılması amaçlanmaktadır.

\section{Kaynaklar}

[1] Yılmaz, H.M., Mutluoğlu, Ö., Ulvi, A., Yaman, A., Bilgilioğlu, S.S., (2018). İnsansız Hava Aracı İle Ortofoto Üretimi Ve Aksaray Üniversitesi Kampüsü Örneği, Geomatik Dergisi, 3,2,103-110.

[2] Cengiz, T., Akbulak, C., Özcan, H., Baytekin, H., (2013). Gökçeada'da Optimal Arazi Kullanımının Belirlenmesi, Tartm Bilimleri Dergisi, 19,148-162.

[3] Dewan, A.M., Yamaguchi, Y., (2009). Using remote sensing and GIS to detect and monitor land use and land cover change in Dhaka Metropolitan of Bangladesh during 1960-2005, Environmental Monitoring and Assessment, 150, 237-249.

[4] Shalaby, A., Tateishi, R., (2007). Remote sensing and GIS for mapping and monitoring land cover and land-use changes in the Northwestern coastal zone of Egypt, Applied Geography, 27,1,28-41.

[5] Hegazy, I.R., Kaloop, M.R., (2015). Monitoring urban growth and land use change detection with GIS and remote sensing techniques in Daqahlia governorate Egypt, International Journal of Sustainable Built Environment, 4, 117-124.

[6] Genç, L., Bostanc1, Y.B., (2007). TROİA Milli Parkı Arazi Kullanım ve Bitki Örtüsü Değişiminin Uzaktan Algılama ve Coğrafi Bilgi Sistemi Yardımıyla Belirlenmesi, Tekirdağ Ziraat Fakültesi Dergisi, 4, 1, 27-41.

[7] Dengiz, O., Demirdağ Turan, İ., (2014). Uzaktan Algılama ve Coğrafi Bilgi Sistem Teknikleri Kullanılarak Arazi Örtüsü / Arazi Kullanımı Zamansal DeğiG̣imin Belirlenmesi: Samsun Merkez Ġlçesi Örneği (1984-2011), Türkiye Tarımsal Araştırmalar Dergisi, 2014, 1, 78-90.
[8] Prasad, A.K., Chai, L., Singh, R.P., Kafatos, M., (2006). Crop yield estimation model for Iowa using remote sensing and surface parameters, International Journal of Applied Earth Observation and Geoinformation, 8, 26-33.

[9] Singh, R., Semwal, D.P., Rai, A., Chhikara, R. S., (2002). Small area estimation of crop yield using remote sensing satellite data, International Journal of Remote Sensing, 23, 1, 49-56.

[10] Bognár, P., Lichtenberger, J., Hamar, D., Tarcsai, G., Timár., Molnár, G., Pásztor, S. Z., Steinbach, P., Székely, B., Ferencz, O. E., Ferencz- Árkos, I., (2010). Crop yield estimation by satellite remote sensing, International Journal of Remote Sensing, $25,20,4113-4149$.

[11] Kaya, Y , Polat, N ., (2020). Investigation Of Phenological Stages of Wheat Plant Using Vegetation Index . Mersin Photogrammetry Journal, 2 (1) , 24-28

[12] Rouse Jr, J., Haas, R. H., Schell, J., Deering, D. W., (1974). Monitoring Vegetation Systems in the Great Plains With ERTS, Third ERTS Symposium, 309319.

[13] Colwell, J. E., Rice, D. P., Nalepka, R. F., (1977). Wheat Yield Forecasts Using Landsat Data, Proceedings of 11th International Symposium on Remote Sensing of Environment, 1245-1254.

[14] Li, Y. Z., (1990). Estimating Production of Winter Wheat by Remote Sensing and Unified Ground Network. II. Nationwide Estimation of Wheat Yields. In Applications of Remote Sensing in Agriculture, 149-158.

[15] Aronoff, S., (1989). Geographic Information Systems: A Management Perspective. Geocarto International, 4, 4, 58 .

[16] Evsahibioğlu, A. N., (2008). Sulu Tarım Alanlarında Küçük Parselli Bitki Desenlerinin Uzaktan Algilanma Potansiyeli. 2. Uzaktan Algllama ve Coğrafi Bilgi Sistemleri Sempozyumu, 305-314.

[17] Raun, W. R., Solie, J. B., Johnson, G. V., Stone, M. L., Lukina, E. V., Thomason, W. E., Schepers, J. S., (2001). In-Season Prediction of Potential Grain Yield in Winter Wheat Using Canopy Reflectance, Agronomy Journal, 93, 1, 131-138.

[18] Şimşek, O., Yıldız, A. M. H., Özaydın, K. A., Çakmak, B., (2007). AgroMetShell Modeli Kullanılarak Türkiye'de Buğdayın Verim Tahmini. Tartm Bilimleri Dergisi, 13, 3, 299-307.

[19] Pinter, P. J., Hatfield, J. L., Schepers, J. S., Barnes, E. M., Moran, M. S., Daughtry, C. S., Uphurch, D. R., (2003). Remote Sensing for Crop Management, 
Photogrammetric Engineering \& Remote Sensing, $69,6,647-664$.

[20] Jiang, D., Yang, X., Clinton, N., Wang, N., (2004). An Artificial Neural Network Model for Estimating Crop Yields Using Remotely Sensed Information, International Journul of Remote Sensing, 25, 9, 1723-1732.

[21] https://earthexplorer.usgs.gov (Son Erişim: 14.07.2020).

[22] https://scihub.copernicus.eu (Son Erişim: 14.07.2020).

[23] Çelik, M. A., Karabulut, M., (2017). Uydu Tabanlı Kuraklık İndisi (SVI) Kullanılarak Yarı Kurak Akdeniz İkliminde (Kilis) Buğday Bitkisinin Kurak Koşullara Verdiği Tepkinin İncelenmesi, Celal Bayar Üniversitesi Sosyal Bilimler Dergisi, 15, 1, 111-130.
[24] Tucker, C. J., Townshend, J. R. G., Goff, T. E., (1985). African Land Cover Classification Using Satellite Data. Science, 9227, 4685, 369-375.

[25] Richardson, A. J., Wiegand, C., (1977). Distinguishing Vegetation From Soil Background Information, Photogrammetric Engineering \& Remote Sensing, 43, 12, 1541-1552.

[26] Gitelson, A.A., (2004). Wide Dynamic Range Vegetation İndex for Remotequantification of Biophysical Characteristics of Vegetation, Journal of Plant Physiology 161, 165-173. 